\title{
Long Term Oxygen Therapy in Patients of COPD in Kashmir - Adherence and Barriers to Adherence
}

\author{
Suhail Mantoo', Umar Hafiz Khan², Mehbooba Rasool ${ }^{3}$, Syed Mudasir Qadri, \\ Sonaullah Shah', Rafi A. Jan', Pravaiz A. Koul ${ }^{7}$
}

\begin{abstract}
${ }_{1}^{1}$ Department of Internal and Pulmonary Medicine, Sheri-Kashmir Institute of Medical Sciences, Soura, Srinagar, Kashmir, India. ${ }^{2}$ Department of Geriatric Medicine, Sheri-Kashmir Institute of Medical Sciences, Soura, Srinagar, Kashmir, India. ${ }^{3}$ Department of Geriatric Medicine, Sheri-Kashmir Institute of Medical Sciences, Soura, Srinagar, Kashmir, India. ${ }^{4}$ Department of Internal and Pulmonary Medicine, Sheri-Kashmir Institute of Medical Sciences, Soura, Srinagar, Kashmir, India. ${ }^{5}$ Department of Internal and Pulmonary Medicine, Sheri-Kashmir Institute of Medical Sciences, Soura, Srinagar, Kashmir, India. ${ }^{6}$ Department of Internal and Pulmonary Medicine, SheriKashmir Institute of Medical Sciences, Soura, Srinagar, Kashmir, India. ${ }^{7}$ Department of Internal and Pulmonary Medicine, Sheri-Kashmir Institute of Medical Sciences, Soura, Srinagar, Kashmir, India.
\end{abstract}

\section{ABSTRACT}

\section{BACKGROUND}

COPD is a growing global threat considering its increasing prevalence, morbidity and mortality. The only modality of treatment that has been proven to alter the late course of this disease is the long term oxygen therapy (LTOT). Considering that an increasing number of COPD patients are getting a prescription of LTOT, this study was done to recognize the common barriers that prevent its adequate compliance.

\section{METHODS}

A pre-set questionnaire was administered to patients and their caregivers regarding LTOT prescription, compliance to LTOT and reasons for their poor compliance to LTOT.

\section{RESULTS}

58 COPD patients included in the study completed the questionnaire. Only 12 (21.4\%) patients used the recommended oxygen for more than 15 hours per day to give them the therapeutic benefit. $21(37.5 \%)$ patients received recommended advice for the duration of using supplemental oxygen each day from their treating physicians. None of the patients received education about the correct use of using oxygen therapy at home.

\section{CONCLUSIONS}

Oxygen usage among patients who have been prescribed home oxygen therapy is far from optimal, and both patient and physician related factors are responsible for it. Thus, the knowledge of major factors responsible for poor compliance of LTOT stresses upon the need for proper education of the treating physician and proper advice and counselling for this treatment modality at the time of prescription, for the patient.

\section{KEY WORDS}

COPD, Long Term Oxygen Therapy, Oxygen Delivery System

\begin{abstract}
Corresponding Author: Dr. Umar Hafiz Khan, Associate Professor, Department of Geriatric Medicine, SKIMS, Srinagar, J\&K, India. E-mail:drumarhafiz@gmail.com

DOI: $10.14260 / \mathrm{jemds} / 2020 / 260$

Financial or Other Competing Interests: None.

How to Cite This Article:

Mantoo S, Hafiz Khan U, Rasool M, et al. Long term oxygen therapy in patients of COPD in Kashmir-adherence and barriers to adherence. J. Evolution Med. Dent. Sci. 2020;9(14):1198-1201, $10.14260 /$ jemds $/ 2020 / 260$
\end{abstract}

Submission 16-12-2019,

Peer Review 13-03-2020

Acceptance 21-03-2020,

Published 06-04-2020.

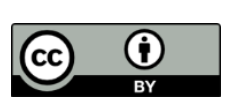




\section{BACKGROUND}

Chronic obstructive pulmonary disease (COPD) is a growing global threat considering its increasing prevalence, morbidity and mortality. The only modality of treatment that has been proven to alter the late course of this disease is the long term oxygen therapy (LTOT). ${ }^{1}$ Two landmark studies, the Nocturnal Oxygen Therapy Trial (NOTT) and the British Medical Research Council (MRC) demonstrated many decades before the survival benefit of LTOT in patients of advanced COPD. ${ }^{2,3}$ The current indications of LTOT in COPD patients include severe resting hypoxemia with $\mathrm{PaO}_{2}<55 \mathrm{mmHg}$ and $\mathrm{PaO}_{2}$ between $55-60 \mathrm{mmHg}$ with evidence of pulmonary hypertension, congestive cardiac failure or polycythemia. ${ }^{4}$ Besides increasing survival, LTOT has also been reported to improve cognitive functions, quality of life, exercise capability and frequency of hospitalizations in COPD..$^{5-11}$

These benefits depend not only on adequate correction of hypoxemia but more importantly on the duration of oxygen usage per day amounting to a minimum of 15 hours per day However, the compliance to LTOT ranges from $45-70 \%$ in different studies. ${ }^{11}$ These studies have been done in resource rich countries. Little data is available for countries with limited resources like India where healthcare is not fully insured. Thus, it becomes imperial to recognize the factors responsible for less use of LTOT, so that measures are adapted to aid patients for proper adherence to this important modality of treatment.

Jammu and Kashmir is the northern state of India with Kashmir being one of its divisions. Considering the high prevalence of COPD in Kashmir $(17.3 \%)^{12}$ and an increasing population of these patients getting a prescription of LTOT, this study was done to recognize the common barriers that prevent the adequate compliance to this important modality of treatment.

\section{METHODS}

This is a descriptive study conducted among COPD patients diagnosed on the basis of symptoms and pulmonary function tests who presented for the first time as out-patients to our tertiary care hospital during the years 2016 to 2017. They were enrolled in the study after obtaining an informed consent. A pre-set questionnaire was administered to patients and their caregivers regarding their disease, LTOT prescription, compliance to LTOT and reasons for their poor compliance to LTOT. The study was approved by the ethical committee of the institute.

\section{RESULTS}

Fifty eight COPD patients included in the study completed the questionnaire. All patients as per their disease severity had received a prescription of long term oxygen therapy (LTOT) according to current guidelines. Median age of patients was 65

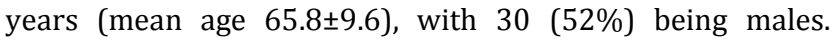
Majority of the patients (89.6\%) were economically dependent on their family for treatment expenses and only $10.3 \%$ of patients were economically independent. Mean duration of COPD diagnosis in these patients was $5.6 \pm 4$ years and the average duration of oxygen usage was 2.2 years. Among a total of 58 LTOT prescriptions, two patients never used any supplemental oxygen because of cost and non-availability respectively. Among 56 patients using supplemental oxygen, $29(51.7 \%)$ patients used oxygen concentrators and the other 27 (48.3\%) used oxygen cylinders. (table 1) However, what is notable is the higher compliance among patients who used concentrators rather than oxygen cylinders (11 out of 29 versus 1 out of 27 respectively).

Figure 1 shows the average number of hours patients used supplemental oxygen each day. It's clear and quiet surprising to know that only 12 (21.4\%) patients used oxygen for more than 15 hours per day to give them the therapeutic benefit of this important modality of treatment.

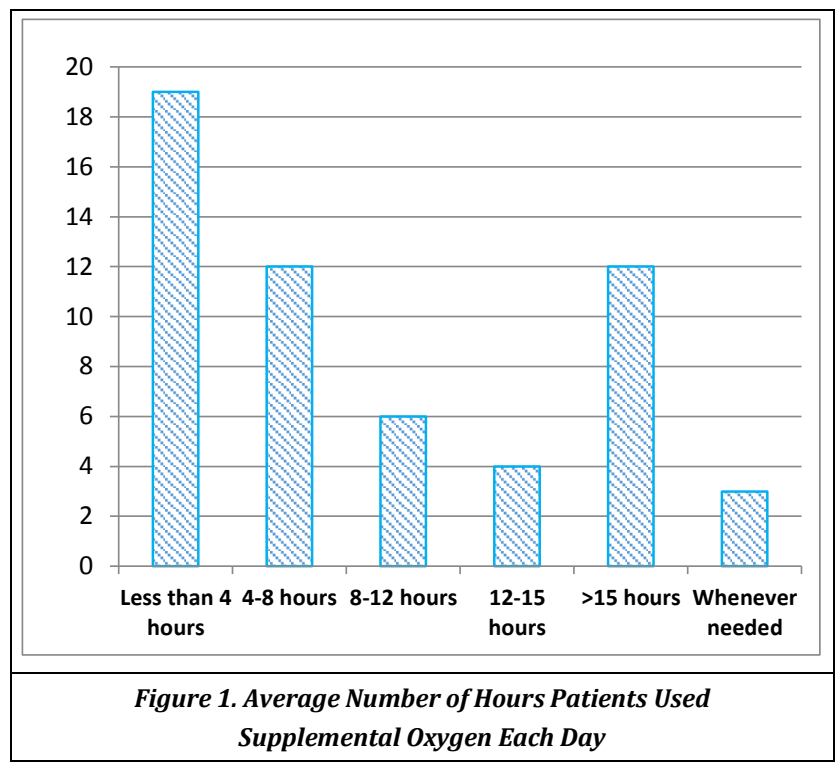

Figure 2 reflects the advice of the prescribing doctors to these patients regarding the each day duration of oxygen usage. Again its quiet surprising to see that only 21 (37.5\%) patients received the correct and recommended advice for the duration of using supplemental oxygen each day.

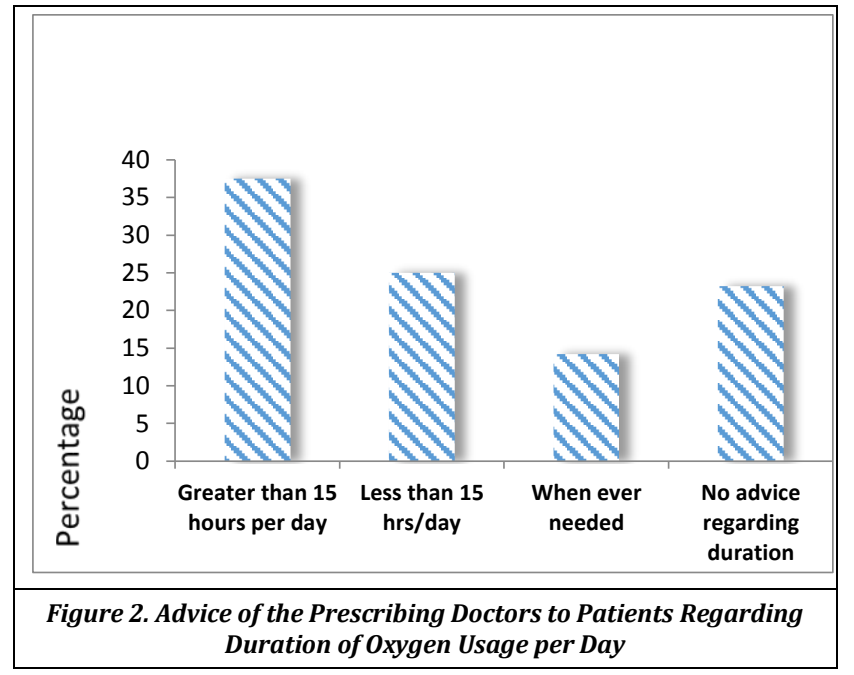

The patients using compressed gas cylinders as the source of their LTOT had two additional reasons to account for the 
extent of their non-compliance, one being the poor availability and other, the practical difficulty in getting the cylinders frequently filled. Amongst 29 concentrator users, 16 patients used oxygen for less than 15 hours each day. Out of 16 noncompliant concentrator users, seven patients were not educated about the minimum daily duration of LTOT required, five patients blamed inadequate power supply to run their concentrators for their poor concentrator usage and four patients reported fear of becoming oxygen dependent if they use oxygen supplement for too many hours each day.

As long term oxygen use on domiciliary basis does have hazards, which although are less reported, the prescribing doctors are required to educate the patients about such potentially preventable hazards reported with LTOT. In our study none of the patients were educated about the risks and potential hazards of LTOT.

\begin{tabular}{|c|c|}
\hline Total Number of Patients (N) & 58 \\
\hline Mean age & $65.8( \pm 9.6)$ years \\
\hline Gender & M: $30(52 \%) ; \mathrm{F}: 28(48 \%)$ \\
\hline Regional distribution & Rural: 29(50\%); Urban: $29(50 \%)$ \\
\hline Dependency & Dependent: $52(90 \%)$ Independent: $6(10 \%)$ \\
\hline $\begin{array}{l}\text { Average monthly income of } \\
\text { independent patients in USD }\end{array}$ & 350 \\
\hline Total oxygen users & 56 \\
\hline Average duration of disease & $5.6( \pm 4.4)$ years \\
\hline Average duration of oxygen usage & 2.2 years \\
\hline Oxygen delivery system used & $\begin{array}{c}\text { Oxygen concentrators: } 29(51.7 \%) \text { Oxygen } \\
\text { Cylinders: } 27(48.3 \%)\end{array}$ \\
\hline
\end{tabular}

\section{DISCUSSION}

This study is the first of its kind in India to know the level of adherence to LTOT amongst patients of COPD and an attempt to identify the important factors responsible for its poor compliance. We found that only $21.4 \%$ of patients used supplemental oxygen for more than 15 hours per day. In contrast, other studies have reported compliance in the range of $45-70 \%$ to this important modality of treatment. ${ }^{11}$ The factors responsible for poor compliance can be divided into the prescription related factors and the patient related factors. In the former group, within our patient population only 21 $(37.5 \%)$ patients received a proper prescription stressing the daily use of LTOT for more than 15 hours. Walshsh et al reported inadequate prescriptions in $45.9 \%$ patients in their study among patients prescribed LTOT. ${ }^{13}$ A similar kind of study by Katsenos et al. reported that $55 \%$ of their patients did not receive proper written instructions about LTOT. ${ }^{14}$

It was in fact surprising to know that in 13 (23.2\%) patients the consulting doctor had not even mentioned the daily duration of LTOT needed. Interpreting it further, among 21 correct prescriptions only $12(57.1 \%)$ patients were compliant in terms of daily duration of LTOT suggesting the presence of other factors contributing to its poor compliance. The type of oxygen delivery system used for LTOT constitutes an important patient related factor affecting the compliance of LTOT. The oxygen storage system can be in the form of compressed gas, liquid or from a concentrator. Oxygen storage system can be either stationary or portable. The two oxygen delivery systems used by our patients were the compressed gas cylinders and the oxygen concentrators. The size of compressed cylinder is defined by their capacity to hold water and range between 1.2 and $6550 \mathrm{~L}$ and are produced in various sizes designated by a capital letter code with $\mathrm{A}$ being the smallest. Commonly used compressed oxygen cylinders are of $\mathrm{E}$ and $\mathrm{M}$ types having a capacity of 660 and 3450 litters respectively. ${ }^{15}$ On an average, the available $\mathrm{E}$ and $\mathrm{M}$ type oxygen cylinders when used for proper time and at a proper flow rate would last their supply of oxygen for an average of 4 6 hours and 2-3 days respectively.

This time can be calculated based on a formula i.e. remaining time is equal to remaining pressure divided by 200 and flow rate used per minute. ${ }^{16}$ Cylinders usually budget an initial cost of five to seven thousand Indian rupees plus charges for their repeated refill and carriage in addition to the amount of productive work hours a person loses while getting a cylinder refilled each time. Oxygen concentrator, on the other hand is an electric device that makes use of a molecular sieve to filter out gases like nitrogen from the atmospheric air and thus providing the concentrated oxygen. With a continuous electric supply, the concentrator promises an advantage of providing an uninterrupted oxygen supply perfect of LTOT. However, in developing countries like ours, the distinct disadvantage continues to be the initial cost of the concentrator.

An average concentrator would cost around fifty thousand Indian rupees plus an odd sum of twenty thousand rupees for a power backup. The third type of delivery system is the liquid oxygen system in which liquid oxygen is gas condensed into a liquid state by extreme cold. Liquid systems have a large reservoir tank and are to be is filled by the oxygen once or twice a month. This system requires no electricity and on a weight to weight basis is approximately 800 times lighter than compressed gas.

However, the liquid oxygen system is costlier and not widely available. Presently the compressed gas cylinders are being used more commonly in India than oxygen concentrators because of the initial lower cost and thus greater affordability, which actually may be fallacious considering the overall usage expenditure in terms of manpower and productive work hours lost in usage of compressed oxygen cylinders. In our study the compliance was found to be higher among patients who used concentrators rather than cylinders, which probably is because of the frequent need to refill the cylinders and the sparse availability of refilling facility in the locality of most patients.

Though supporting oxygen concentrators as a relative compliant source of oxygen supply for LTOT, 16 out of 27 concentrator users (i.e. 59.2\%) in our study population used oxygen for less than 15 hours each day. The reasons put forth by the patients with poor compliance to concentrators as mentioned above would again indirectly blame the prescribing physician for not educating their patients regarding their disease as well as the way of using this treatment modality. Although oxygen therapy is almost always thought of saving lives when used in acute settings and has well recognized benefits on long term use as well.

Accidents related to long term oxygen use although rare are well recognized in terms of increased chances of accidental fire injuries and fatalities. Besides, the other physical hazards due to cylinder explosions are reported as well. ${ }^{17}$ Thus, it becomes imperative on part of the treating doctor to educate the patients about the possibility of such accidents and the necessary precautions required to prevent them. It was 
evident in our study, that none of our patients were educated regarding the potential harms of LTOT and the precautions necessary to prevent them.

\section{CONCLUSIONS}

Oxygen usage among patients who have been prescribed home oxygen therapy is far from optimal, and both patient and physician related factors are responsible for it. Thus, the knowledge of major factors responsible for poor compliance of LTOT stresses upon the need for proper education of the treating physician and proper advice and counselling for this treatment modality at the time of prescription, for the patient. The adherence to long term oxygen therapy remains poor. In addition to the socio-economic factors, the treating doctors or specialists remain greatly responsible for such a poor utilization of this important modality of treatment. We therefore suggest exploiting the physician-patient relationship in making the patients understand in detail the benefits of this treatment.

\section{REFERENCES}

[1] Katsenos S, Constantopoulos SH. Long-term oxygen therapy in COPD: factors affecting and ways of improving patient compliance. Article ID 325362, Pulmonary Medicine 2011;2011:1-8.

[2] Kvale PA, Conway WA, Coates EO. Continuous or nocturnal oxygen therapy in hypoxemic chronic obstructive lung disease: a clinical trial. Nocturnal Oxygen Therapy Trial Group. Annals of Internal Medicine 1980;93(3):391-8.

[3] Harris CS, Bishop JM, Clark TJH. Long term domiciliary oxygen therapy in chronic hypoxic cor pulmonale complicating chronic bronchitis and emphysema. Report of the Medical Research Council Working Party. Lancet 1981;317(8222):681-6.

[4] Gold Initiative for Chronic Obstructive Lung Disease. 2019. Global strategy for the diagnosis, management, and prevention of chronic obstructive pulmonary disease. https://goldcopd.org/wpcontent/uploads/2017/11/GOLD-2018-v6.0-FINAL-
revised-20-Nov_WMS.pdf. (Accessed 21st February, 2019)

[5] Crockett AJ, Cranston JM, Moss JR, et al. A review of longterm oxygen therapy for chronic obstructive pulmonary disease. Respir Med 2001;95(6):437-43.

[6] Eaton T, Lewis C, Young $P$, et al. Long-term oxygen therapy improves health-related quality of life. Respir Med 2004;98(4):285-93.

[7] Mitrouska I, Tzanakis N, Siafakas NM. Oxygen therapy in chronic obstructive pulmonary disease. European Respiratory Monograph 2006;11(38):302-12.

[8] Wedzicha JA. Effects of long-term oxygen therapy on neuropsychiatric function and quality of life. Respiratory Care 2000;45(1):119-26.

[9] Kim V, Benditt J0, Wise RA, et al. Oxygen therapy in chronic obstructive pulmonary disease. Proceedings of The American Thoracic Society 2008;5(4):513-8.

[10] Ringbaek TJ, Viskum K, Lange P. Does long-term oxygen therapy reduce hospitalization in hypoxaemic chronic obstructive pulmonary disease? European Respiratory Journal 2002;20(1):38-42.

[11] Morrison DA, Stovall JR. Increased exercise capacity in hypoxemic patients after long-term oxygen therapy. Chest 1992;102(2):542-50.

[12] Burney P, Jithoo A, Kato B, et al. Chronic obstructive pulmonary disease mortality and prevalence: the associations with smoking and poverty - a BOLD analysis. Thorax 2014;69(5):465-73.

[13] Walshaw MJ, Lim R, Evans CC, et al. Factors influencing the compliance of patients using oxygen concentrators for long-term home oxygen therapy. Respiratory Medicine 1990;84(4):331-3.

[14] Katsenos S, Froudarakis ME, Charisis A, et al. Long-term oxygen therapy in Ioannina. Respiration 2004;71(6):61924.

[15] Sandberg W, Urman R, Ehrenfeld J. The MGH textbook of anesthetic equipment. $1^{\text {st }}$ edn. London: Elsevier Saunders 2010.

[16] Atlas G. A method to quickly estimate remaining time for an oxygen E-cylinder. Anesthesia Analgesia 2004;98(4):1190.

[17] Cooper BG. Home oxygen and domestic fires. Breathe (Sheff) 2015;11(1):4-12. 